\title{
Viscosity Evaluation of Simulated Foaming Slag via Interfacial Reaction at Room Temperature
}

\author{
Shota HATANO, ${ }^{1)}$ Shogo HAYASHI, ${ }^{2)}$ Noritaka SAITO ${ }^{1) *}$ and Kunihiko NAKASHIMA ${ }^{1)}$ \\ 1) Department of Materials, Kyushu University, 744 Motooka Nishi-ku, Fukuoka, 819-0395 Japan. \\ 2) TOTO LTD., 2-1-1, Nakashima, Kokurakita-ku, Kitakyushu, 802-8601 Japan.
}

(Received on November 4, 2020; accepted on January 5, 2021; J-STAGE Advance published date: May $21,2021)$

\begin{abstract}
$\mathrm{CaO}-$ based slag used in hot metal pretreatment and converters in steelmaking processes typically contains dispersed gas phases. This is called foaming slag, which is known to degrade the quality of slag. The rheological behavior of this slag is dependent on the dispersed part of the gas phase. This gas is generated by the chemical reaction between the hot metal and the slag. In this study, simulated foaming slag was prepared by reacting sodium hydrogen carbonate and oxalic acid in glycerol, which disperses carbon dioxide. Next, we systematically investigated the effects of the volume fraction of the dispersed gas phase and the proportion of glycerol on the viscosity and bubble diameter. According to the model used in this study, the bubbles were smaller than those in the model in which the gas was directly dispersed. The bubble size increased as the gas phase ratio and liquid viscosity increased, likely because the bubble growth is promoted by increase in the gas phase ratio and liquid phase viscosity, and the frequency with which the bubbles contact one other. The increase of the gas phase ratio at low liquid-phase viscosity and low shear rate caused an increase in both apparent viscosity and relative viscosity, which was obtained by dividing the apparent viscosity by liquid-phase viscosity. However, these increases in viscosity were not observed at a high shear rate. This is likely because the mechanism of bubble diffusion and flow is affected by the liquid-phase viscosity and shear rate. We found that the model in this study exemplified a Herschel-Bulkley fluid. In addition, we proposed an equation for measuring viscosity from the gas phase ratio.
\end{abstract}

KEY WORDS: foaming slag; viscosity; bubble diameter; gas phase ratio; viscoelasticity; Herschel-Bulkley Fluid.

\section{Introduction}

In the steel refining process, the following reactions occur due to the presence of $\mathrm{C}$ and $\mathrm{FeO}$ in the slag from the hot metal during pretreatment processes such as desiliconization, dephosphorization, and desulfurization. ${ }^{1)}$

$$
\mathrm{C}+\mathrm{O} \rightarrow \mathrm{CO}
$$

The CO gas generated by the reaction in Eq. (1) transports the hot metal upwards, and the slag in a gas-liquidcoexisting state is generated. The product, iron, is dispersed in this slag, decreasing its recovery efficiency. ${ }^{2)}$ Therefore, it is necessary to reduce the slag loss of iron particles. It is also known that the quality of slag deteriorates when air bubbles and iron particles are present in the slag. ${ }^{3)}$ Therefore, for efficient steel refining, accurate evaluation of the behavior and physical properties of gas-liquid-coexisting slag and controlled slag formation are important. The Stokes equa-

\footnotetext{
* Corresponding author: E-mail: saito.noritaka.655@m.kyushu-u.ac.jp
}

tion $^{4)}$ is shown in Eq. (2).

$$
u=\frac{d_{p}^{2} 2\left(\rho_{p}-\rho_{f}\right) g}{18 \eta},
$$

where $\mathrm{u}$ is sedimentation velocity, $\mathrm{d}_{\mathrm{p}}$ is the particle size, $\rho_{\mathrm{p}}$ is the particle density, $\rho_{\mathrm{f}}$ is the fluid density, $\mathrm{g}$ is the gravitational acceleration, and $\eta$ is the fluid viscosity. Based on Eq. (2), to effectively improve the recovery rate of granular iron, the sedimentation rate of granular iron must be increased by reducing the viscosity of the slag itself. However, it is difficult to understand the viscous behavior of the foaming slag at high temperature in the furnace. In addition, the occurrence of a refining reaction between the slag and molten iron, a corrosion reaction with the refractory, and slag after pretreatment are observed.

Although understanding the physical properties of slag is as crucial as controlling the foaming slag, ${ }^{5-8)}$ the information in the viscosity of multiphase gas-liquid slags is currently lacking. Therefore, modeling of the gas-liquid-coexisting slag at room temperature and accumulation of slag forming 
data have been widely carried out. Sibree ${ }^{9)}$ first confirmed that the viscosity of the liquid phase increases with the suspension of the gas. Uhira ${ }^{10)}$ measured the viscosity of silicone oil and bubble suspension by varying the volume fraction of the gas phase. In various other fields, studies have also been conducted to elucidate the viscous behavior of gas-liquid-coexisting liquids. ${ }^{11,12)}$ For instance, some of the authors ${ }^{13)}$ measured the viscosity by nitrogen-dispersed silicone oil-based foaming slag and reported that the relative viscosity increased with the gas phase ratio and the fluid transitioned from a Newtonian fluid to a pseudo-plastic fluid at a certain gas phase ratio. Many of the aforementioned models were created by blowing gas from the outside; however, in the pretreatment process of hot metal, the reaction of Eq. (1) occurs. These models of foaming slag are not a suitable reproduction of the actual slag-forming process because the gas is generated by the chemical reaction. Therefore, investigating the effect of internally generated gas on the viscous behavior of a fluid is essential for a highly accurate flow simulation. In this study, we attempted to investigate the influence of internally generated gas on the viscous behavior of a fluid by measuring the viscosity of a model created using internally generated gas.

In the past, Qic et al. ${ }^{14)}$ investigated foaming by using a model in which oxalic acid was injected into a mixed solution of glycerol and sodium hydrogen carbonate to generate $\mathrm{CO}_{2}$. Therefore, in this study, in order to elucidate the viscous behavior of gas-liquid-coexisting slag derived from internally generated gas, the foam viscosity was measured at room temperature by using the model by Qic et al. First, the effect of viscosity was systematically evaluated. The estimated values were compared with the measured data of a simulated foaming slag prepared by dispersing $\mathrm{N}_{2}$ gas in silicone oil. The purpose of this study was to develop a formula for calculating viscosity from the gas phase ratio by organizing the measured viscosity values according to each condition.

\section{Experimental}

\subsection{Modeling of Foaming Slag Resulting from Inter- nally Generated Gas}

In this study, the measurement was performed using a viscosity measuring device with a rotating inner cylinder. Table 1 shows the measurement conditions and Fig. 1 shows a schematic diagram of the measurement equipment. To simulate the slag at room temperature, a previously reported method ${ }^{14)}$ by G. Qic et al. was referred to, in which a mixture of glycerol and $\mathrm{NaHCO}_{3}$ was placed in a cylindrical tube, and $\mathrm{C}_{2} \mathrm{H}_{2} \mathrm{O}_{4}$ was fed from the inlet at the bottom of the device. According to Eq. (3), $\mathrm{CO}_{2}$ is generated, allowing the production of a gas-liquid-coexisting fluid, which is used as a measurement sample.

$$
\mathrm{C}_{2} \mathrm{H}_{2} \mathrm{O}_{4}+2 \mathrm{NaHCO}_{3} \rightarrow \mathrm{Na}_{2} \mathrm{C}_{2} \mathrm{O}_{4}+2 \mathrm{CO}_{2}+2 \mathrm{H}_{2} \mathrm{O} \ldots
$$

In previous studies, methods for determining the gas phase ratio have been investigated, such as obtaining the ratio of the bubble blowing height to the original height and measuring the void ratio from a cross-sectional photograph of the blown bubbles. ${ }^{15,16)}$ In this experiment, the gas phase ratio was determined as follows. The foam height, $h_{\text {foam }}$, is expressed by the following formula, where $h_{0}$ is the height
Table 1. Experimental conditions for viscosity evaluation.

\begin{tabular}{cc}
\hline Gas phase ratio (vol\%) & $32.4,47.7,70.6$ \\
Viscosity of aqueous glycerol (mPa $\cdot \mathrm{s})$ & $1.76,6.00,60.1,100$ \\
Spindle speed (rpm) & $5,10,20,50,100$ \\
\hline
\end{tabular}

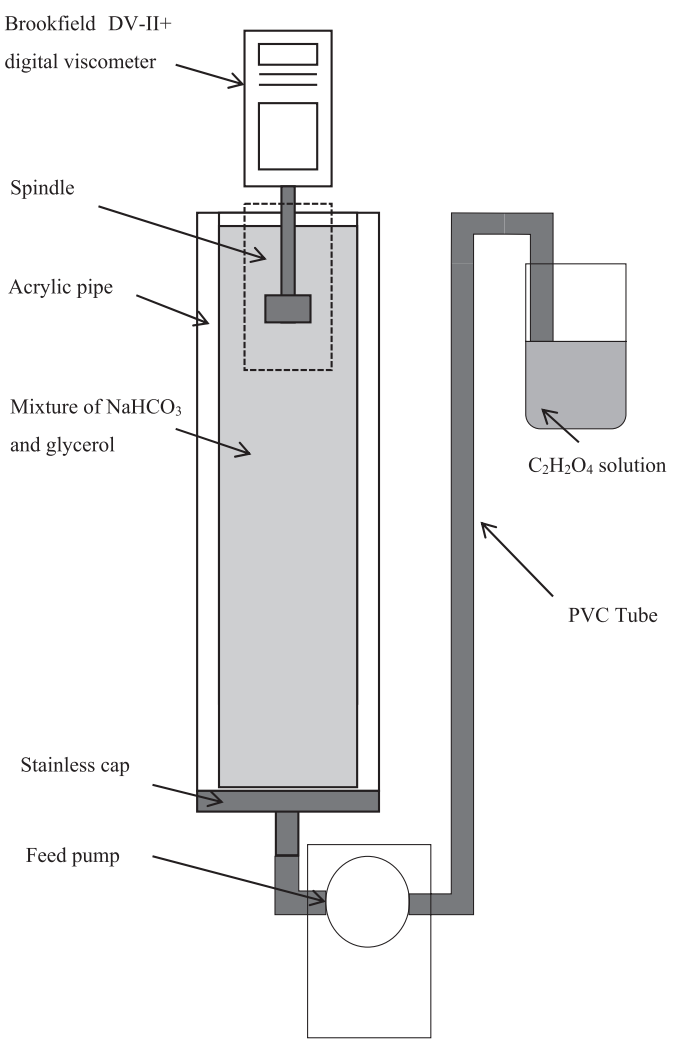

Fig. 1. Schematic illustration of the experimental apparatus.

when the foam reaches a certain position and $h_{\text {liquid }}$ is the height of the liquid surface after oxalic acid injection.

$$
h_{\text {foam }}=h_{0}-h_{\text {liquid }}
$$

From the ratio of the height of the whole system to the height of the foam, the gas phase ratio, $\phi$, is expressed by the following equation.

$$
\phi=\frac{h_{\text {foam }}}{h_{0}}=\frac{h_{0}-h_{\text {liquid }}}{h_{0}}
$$

Due to the gas generated by the chemical reaction, it is difficult to accurately control the amount of gas. Therefore, as a preliminary experiment, we investigated the foam height of the reaction and controlled the concentration and quantity of $\mathrm{NaHCO}_{3}$ and $\mathrm{C}_{2} \mathrm{H}_{2} \mathrm{O}_{4}$ during the measurement of liquid phase viscosity and gas phase ratio in order to achieve appropriate forming.

\subsection{Measurement of Bubble Diameter and Viscosity in Gas-liquid-coexisting Fluid by Internally Gener- ated Gas}

A microscope (VHX-200, KEYENCE) was inserted into an acrylic pipe and fixed so that the bottom of the lens covered the test tube that was immersed $2.5 \mathrm{~cm}$ from the liquid surface. Then, forming was performed as described in section 2.1, and the bubbles in the fluid were photographed by 
shining a light from the side of the acrylic pipe. By changing the concentration of aqueous glycerol (20 mass $\%, 35$ mass $\%$, 50 mass $\%, 65$ mass $\%$ and 80 mass $\%$ ), the liquid viscosity $(1.76 \mathrm{mPa} \cdot \mathrm{s}, 3.00 \mathrm{mPa} \cdot \mathrm{s}, 6.00 \mathrm{mPa} \cdot \mathrm{s}, 27.5 \mathrm{mPa} \cdot \mathrm{s}$ and 60.1 $\mathrm{mPa} \cdot \mathrm{s})$ and gas phase ratio $(32.4 \mathrm{vol} \%, 47.7 \mathrm{vol} \%$ and 70.6 vol\%) were systematically changed. Because the actual viscosity of molten slag lies between 1.0 and $10^{5} \mathrm{mPa} \cdot \mathrm{s}$, we used aqueous glycerol. It exhibits a similar range of viscosity and can dissolve $\mathrm{NaHCO}_{3}$. A total of 30 bubbles were randomly selected from the photographs; their diameters were measured, and the average value was used as the bubble diameter.

The spindle corresponds to the inner cylinder and the acrylic pipe fixed to the pedestal corresponds to the outer cylinder. Two types of spindles were used according to the viscosity of liquid phase. The outer diameters of the inner cylinder are 27.5 and $14.5 \mathrm{~mm}$ and the inner diameter of the outer cylinder is $40 \mathrm{~mm}$. The larger spindle was used in the lower liquid phase viscosities of $1.76 \mathrm{mPa} \cdot \mathrm{s}$ and $6.00 \mathrm{mPa} \cdot \mathrm{s}$, and the smaller spindle was used in the higher liquid phase viscosities of $60.1 \mathrm{mPa} \cdot \mathrm{s}$ and $100 \mathrm{mPa} \cdot \mathrm{s}$. After preparing the gas-liquid-coexisting fluid, the viscosity of glycerol (1.76 $\mathrm{mPa} \cdot \mathrm{s}, 6.00 \mathrm{mPa} \cdot \mathrm{s}, 60.1 \mathrm{mPa} \cdot \mathrm{s}$, and $100 \mathrm{mPa} \cdot \mathrm{s})$, gas phase ratio (32.4 vol\%, $47.7 \mathrm{vol} \%$ and $70.6 \mathrm{vol} \%)$, and spindle speed ( $5 \mathrm{rpm}, 10 \mathrm{rpm}, 20 \mathrm{rpm}, 50 \mathrm{rpm}$ and $100 \mathrm{rpm}$ ) were changed, and the measurement of viscosity was performed using a viscometer (DV-II+, AMETEK Brookfield). The viscosity of the actual slag is approximately $0.001-100$ $\mathrm{Pa} \cdot \mathrm{s}$, the gas phase rate of the actual foaming slag is $\sim 70-80$ vol $\%{ }^{17)}$ There is little data on the shear rate of slag in actual operations. However, the spindle speed for measuring the slag viscosity in laboratory conditions is approximately 10-400 rpm. In this experiment, each parameter is set to take a value in this range.

\section{Results and Discussion}

\subsection{Bubble Diameter Measurement}

Images of bubbles for different liquid-phase viscosities and gas phase ratio are shown in Figs. 2 and 3, respectively. From the images, it was observed that the bubble diameter tended to increase with the increase in the liquid phase viscosity and gas phase ratio. Figure 4 shows the bubble diameter of gas-liquid-coexisting fluid as a function of gas phase ratio. Meanwhile, Fig. 5 displays the bubble diameter of gas-liquid-coexisting fluid as a function of the viscosity of the glycerol aqueous solution. In these graphs, (a) shows the bubble diameters of the simulated foaming slag from internally generated gas and (b) presents the bubble diameters of the simulated foaming slag prepared by dispersing $\mathrm{N}_{2}$ gas in silicone oil using the same measurement device. The bubble diameter is given as a function of the gas phase ratio and liquid phase viscosity, respectively. As shown in Fig. 4, the bubble size increased as the gas phase ratio and liquid phase viscosity increased.

The Young-Laplace equation ${ }^{18)}$ is shown in Eq. (6). $\Delta P$ is the pressure difference between the inside and outside of the foam film, $\gamma$ is the surface tension, and $R$ is the radius of curvature.

$$
\Delta P=\gamma / R
$$

This equation shows that $\Delta \mathrm{P}$ is inversely proportional

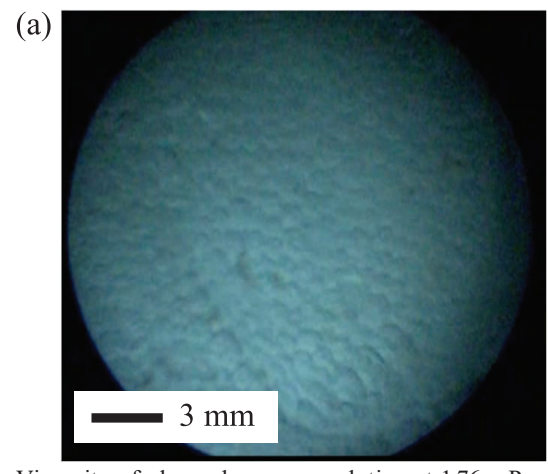

Viscosity of glycerol aqueous solution at $1.76 \mathrm{mPa} \cdot \mathrm{s}$ Gas phase ratio 47.7 vol\%.

(b)

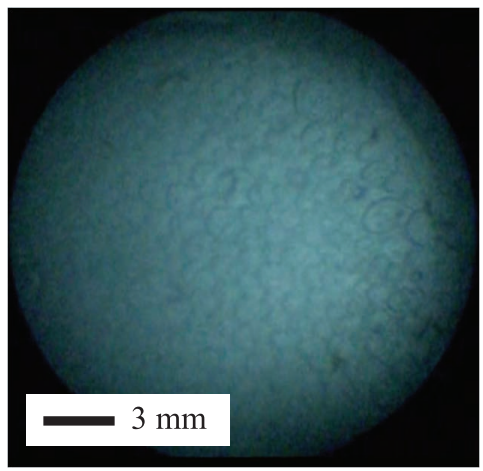

Viscosity of glycerol aqueous solution at $6.00 \mathrm{mPa} \cdot \mathrm{s}$ Gas phase ratio $47.7 \mathrm{vol} \%$.

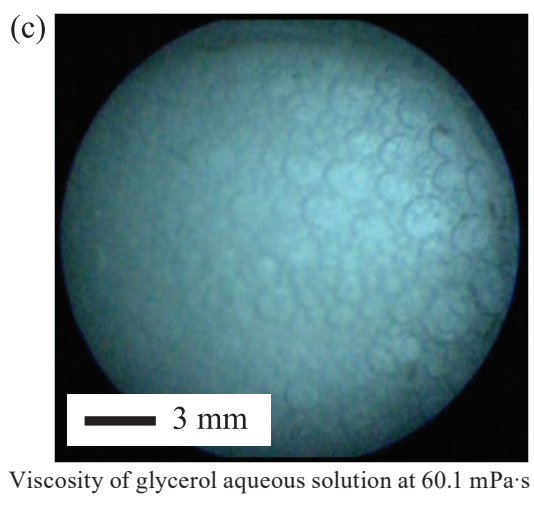

Gas phase ratio 47.7 vol\%.

Fig. 2. Images of bubbles for diameter measurement at (a) 1.76 (b) 6.00 , and (c) $60.1 \mathrm{mPa} \cdot \mathrm{s}$ of aq. glycerol solution. (Online version in color.)

to R. Therefore, when bubbles of different sizes come into contact with each other, the gas diffuses from the small bubbles with low internal pressure to the large bubbles with high internal pressure in order to reduce the pressure inside the bubbles. Therefore, small bubbles become smaller and disappear, and large bubbles become larger. As the gas phase ratio increases, the number of bubbles and foaming height also increase. As the number of bubbles increases, the frequency with which bubbles contact one other increases. In addition, as the foaming height rises, the measurement position of the bubble diameter rises. This means that the time taken for the gas generated in the lower part of the measurement equipment to reach the measurement position increases; thus, there is sufficient time for the gas to dif- 
(a)

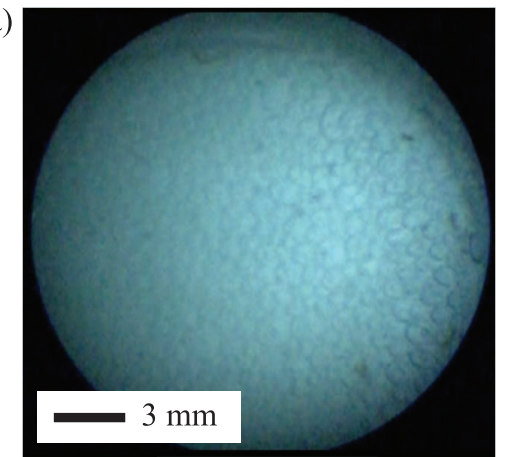

Viscosity of glycerol aqueous solution at $6.00 \mathrm{mPa} \cdot \mathrm{s}$ Gas phase ratio 32.4 vol\%.

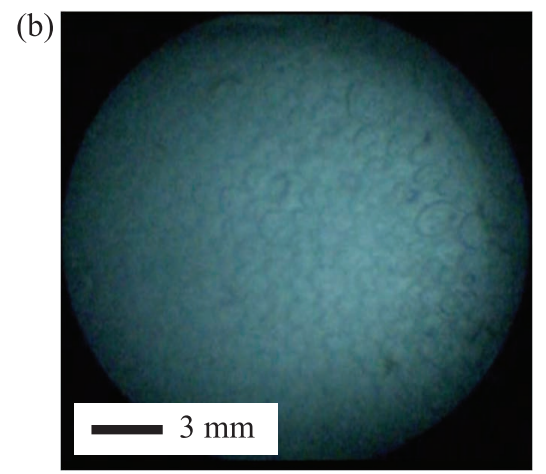

Viscosity of glycerol aqueous solution at $6.00 \mathrm{mPa} \cdot \mathrm{s}$ Gas phase ratio 47.7 vol $\%$.

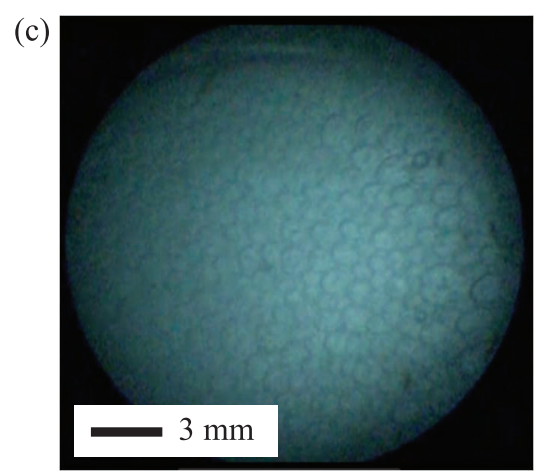

Viscosity of glycerol aqueous solution at $6.00 \mathrm{mPa} \cdot \mathrm{s}$ Gas phase ratio 70.6 vol\%.

Fig. 3. Images of bubbles for diameter measurement at (a) 32.4, (b) 47.7 , and (c) $70.6 \mathrm{vol} \%$ of gas phase ratio. (Online version in color.)

fuse between the bubbles. Therefore, it is considered that the diffusion of gas between bubbles is promoted, which leads to an increase in bubble diameter. In addition, as the liquid viscosity increases, it takes a long time for the simulated foaming slag to disappear, so the bubbles contact each other, allowing time for the gas to diffuse between the bubbles. Therefore, it is considered that the bubble diameter increases as the liquid viscosity increases.

Comparing the data from (a) and (b) in Figs. 4 and 5, the bubble diameter of the foaming slag produced by blowing gas was $\sim 0.5-1 \mathrm{~mm}$ larger, even when the gas phase ratio and liquid phase viscosity were comparable.

When the gas is blown to form bubbles, the buoyancyand surface-tension-induced forces balance. Surface tension is $\sigma$, gravitational acceleration is $g$, density difference between liquid and gas is $\rho$, bubble radius is $R$, and radius
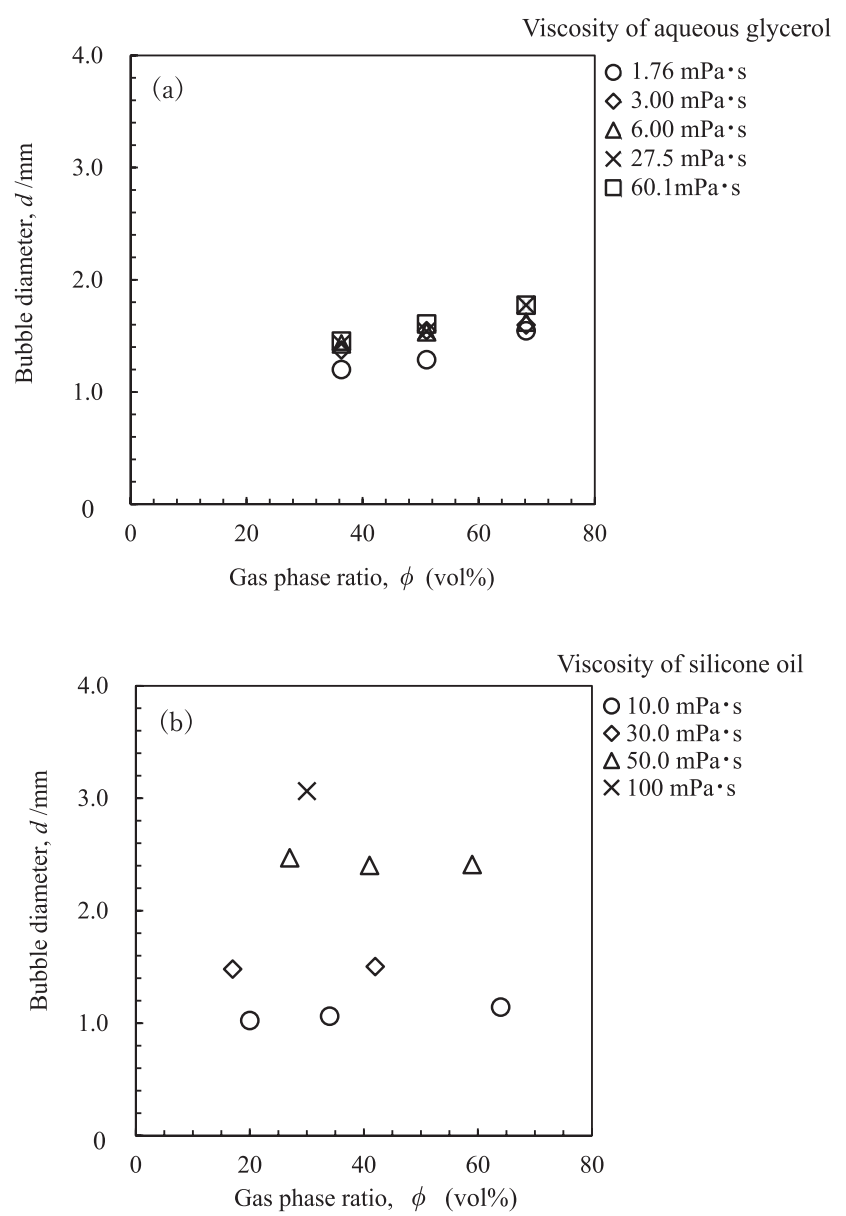

Fig. 4. Bubble diameter of a double-phase fluid as a function of volume fraction of bubbles (a) from internally generated gas and (b) by dispersing $\mathrm{N}_{2}$ gas from outside.

of gas pipe is $r$, buoyancy is $\left(4 \pi \mathrm{R}^{3} \rho \mathrm{g}\right) / 3$, and force generated by surface tension is $2 \pi \mathrm{r} \sigma$. Since these two forces are in balance, rearranging the bubble radius, $R$, gives the following formula. ${ }^{19)}$

$$
R^{3}=\frac{3 r \sigma}{2 \rho g}
$$

From Eq. (7), the bubble diameter when the gas is blown is proportional to the radius of the gas inlet pipe. Therefore, the bubble diameter in the model of the externally derived gas depends on the pore diameter of the porous material. The porous material is used to disperse the gas.

\subsection{Viscosity Measurement of Simulated Foaming Slag}

Figure 6 shows the apparent viscosity of the fluid due to the change in the gas phase ratio for different liquid phase viscosities and at different rotational speeds. The apparent viscosity increases with the gas phase ratio in the low liquid viscosity at low shear rates, but not at high liquid viscosity and high shear rate.

In the low liquid-phase viscosity region (1.76 and 6.00 $\mathrm{mPa} \cdot \mathrm{s})$, the viscosity of the fluid increases rapidly when the rotational speed is low. However, as the spindle speed increases, the forming viscosity increases slowly. To consider this tendency, the properties of the form must be taken into account. According to the previously reported models, foaming, which generates high-density fine air bubbles, 

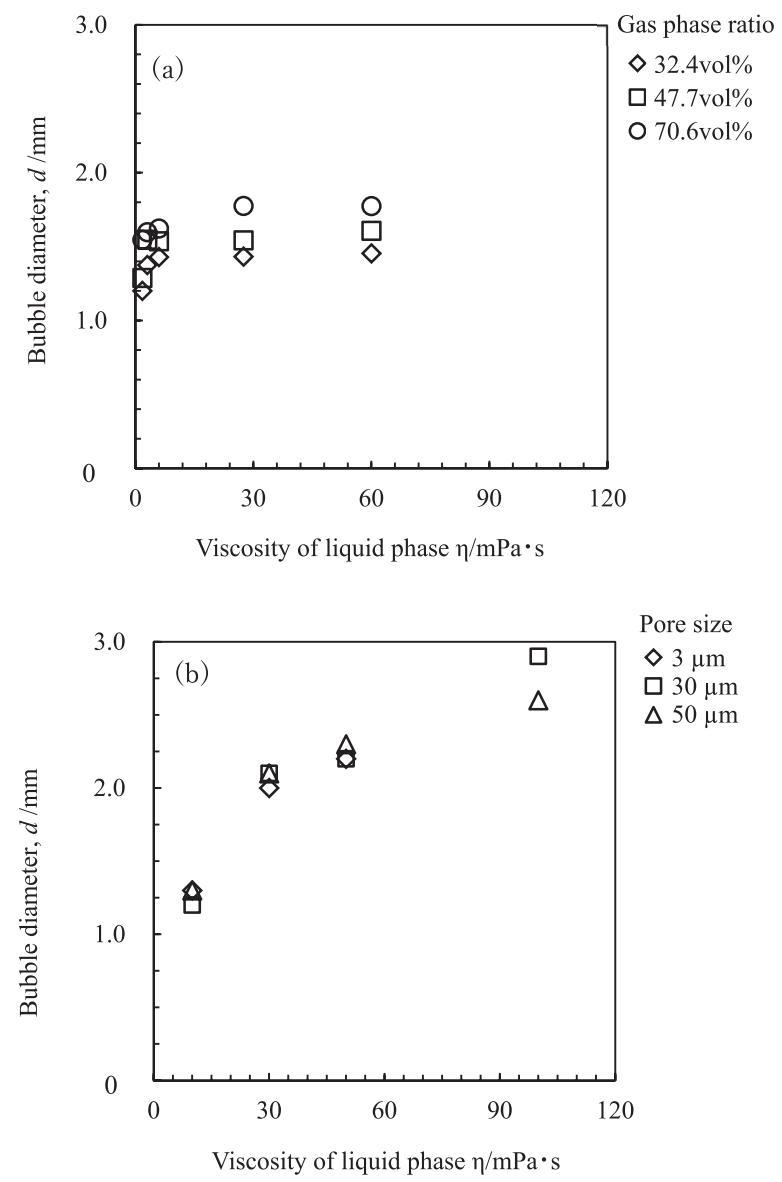

Fig. 5. Bubble diameter of a double-phase fluid as a function of viscosity of the glycerol aq. solution (a) from internally generated gas (b) by dispersing $\mathrm{N}_{2}$ gas from outside.
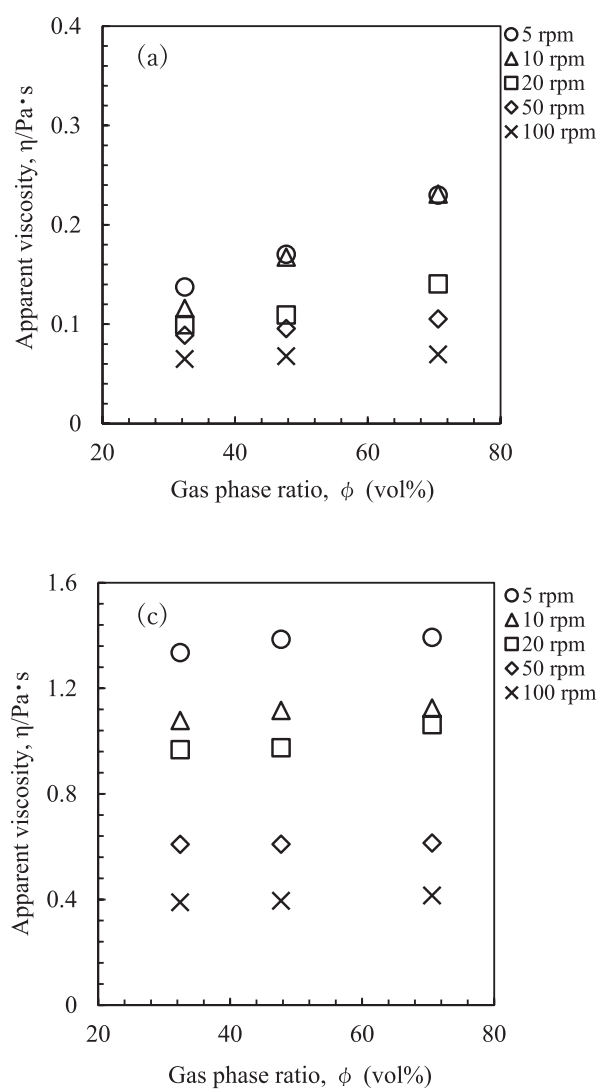

promotes the formation of a viscoelastic body. ${ }^{20,21)} \mathrm{A}$ viscoelastic body has both elasticity, which is a solid property, and viscosity, which is a liquid property. At low shear rates, bubbles move around the spindle non-uniformly and diffuse intermittently. ${ }^{20)}$ The shear stress at low shear rates is dominated by the repulsive force due to the elastic component, and the magnitude of this repulsive force increases in proportion to the number of bubbles. On the other hand, at a high shear rate, the bubbles around the spindle form laminar lanes in the shear direction. As a result, the shear stress is dominated by the frictional force due to the viscous component. ${ }^{20)}$ The magnitude of this frictional force is determined by the difference in velocity between adjacent bubbles and does not depend on the number of bubbles. Therefore, it is considered that at a low shear rate, the viscosity of the fluid increases depending on the gas phase ratio, but at a high shear rate, the viscosity decreases. For high liquid-phase viscosities of 60.1 $\mathrm{mPa} \cdot \mathrm{s}$ and $100 \mathrm{mPa} \cdot \mathrm{s}$, there was almost no increase in the apparent forming viscosity because of the gas phase ratio. It is considered that in the high-viscosity liquid phase, bubbles were less likely to diffuse or flow due to the high viscosity of the liquid film and were not affected by the gas phase ratio.

Figure 7 shows the relative viscosity of the fluid ascribed to the change in the gas phase ratio for different liquid phase viscosities and at different rotational speeds. The relative viscosity is calculated by dividing the apparent viscosity of a gas-liquid-coexisting fluid by the liquid phase viscosity $\left(\eta_{\mathrm{L}}\right)$. It indicates how difficult it is for the fluid to move with respect to the liquid phase. As the apparent viscosity is divided by $\eta_{\mathrm{L}}$, the overall tendency is equal to the apparent viscosity. In high liquid-phase viscosities of $60.1 \mathrm{mPa} \cdot \mathrm{s}$ and
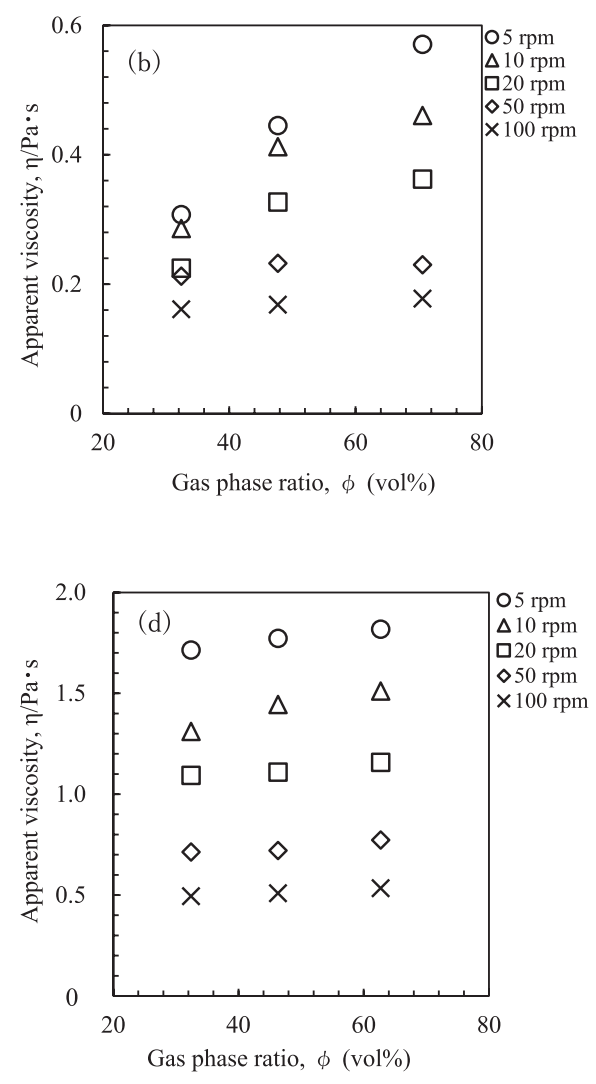

Fig. 6. Apparent viscosity of a double-phase fluid as a function of the volume fraction of bubbles at (a) 1.76, (b) 6.00, (c) 60.1, and (d) $100 \mathrm{mPa} \cdot \mathrm{s}$ of aq. glycerol solution. 

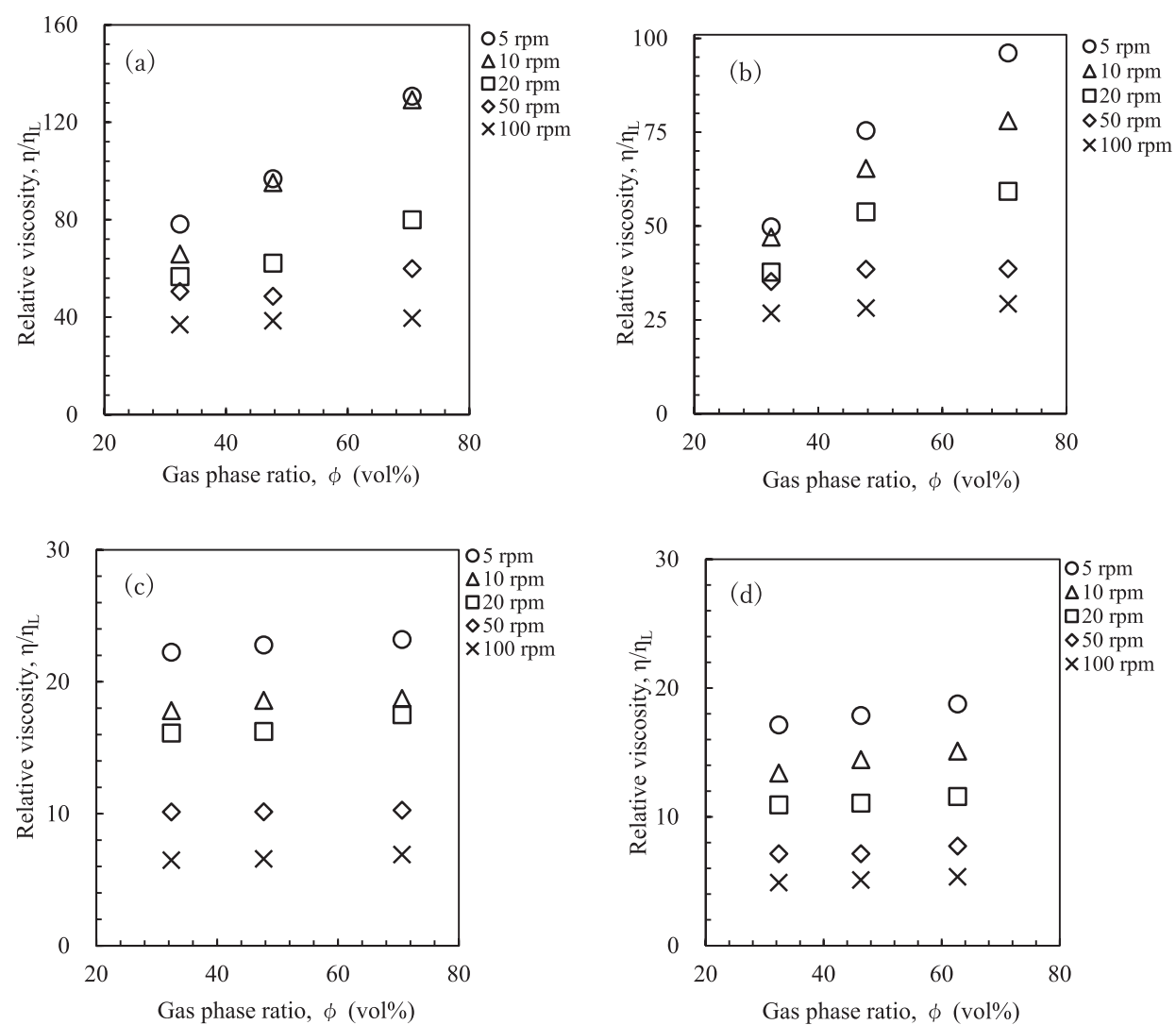

Fig. 7. Relative viscosity of double phase fluid as a function of volume fraction of bubbles at (a) 1.76, (b) 6.00, (c) 60.1, and (d) $100 \mathrm{mPa} \cdot \mathrm{s}$ glycerol aq. solution.
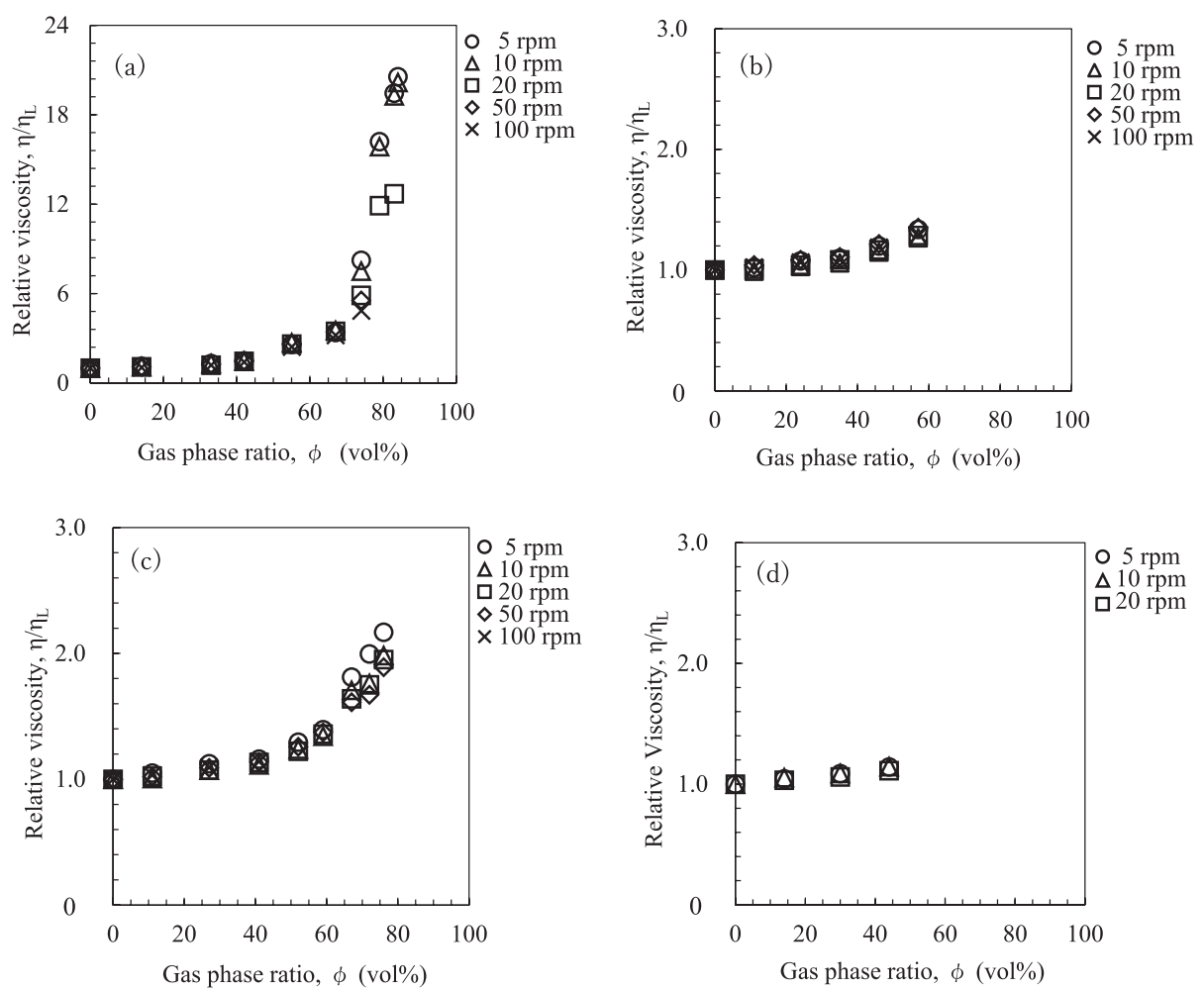

Fig. 8. Relative viscosity of $\mathrm{N}_{2}$ blowing gas foaming at (a) 10 , (b) 30 , (c) 50 , and (d) $100 \mathrm{mPa} \cdot \mathrm{s}$ of silicone oil (pore size of porous alumina: $30 \mu \mathrm{m}$ ).

$100 \mathrm{mPa} \cdot \mathrm{s}$, the relative viscosity was about 20 times higher than the liquidus viscosity, while in the low liquid-phase viscosity region $(1.76$ and $6.00 \mathrm{mPa} \cdot \mathrm{s})$ it was 100 times higher. This is extremely high.

For comparison, Fig. 8 shows the relative viscosity when $\mathrm{N}_{2}$ was blown into silicone oil to produce a gas-liquid- 
coexisting fluid. Comparing Figs. 7 and 8, even if the liquid viscosities are similar, the forming due to the gas generated by the reaction shows a higher relative viscosity value than that due to the injected gas. The bubbles generated by the reaction are finer than the bubbles generated by the blown gas. The density of fine bubbles is higher than that of coarse bubbles, increasing the number of bubbles per unit volume as well as the resistance, such as repulsion and friction, between bubbles, so that the effect of obstructing the flow increases. Therefore, it is considered that the forming by the reaction-generated gas showed a higher viscosity value. In Fig. 8, the difference in the slope of the graph due to the change in the number of revolutions in the low-viscosity liquid phase was not observed because of the fact that the effect of bubble dispersion did not appear because the gas was always supplied from the bottom.

In Figs. 6 and 7, the apparent viscosity and relative viscosity decrease with increasing shear rate for all liquidphase viscosities and gas phase ratio. This is a behavior unique to non-Newtonian fluids. On the other hand, in the low gas-phase region in Fig. 8, no change in viscosity due to shear rate is observed. This is the behavior of a Newtonian fluid. In order to investigate the behavior of the fluid created in this experiment in more detail, the shear rate and shear stress were calculated from the experimental conditions of time and measured apparent viscosity (Fig. 9). At any viscosity and gas phase ratio, the shear stress increased with shear rate as a convex curve. It was also found that the finite yield stress was obtained when the shear rate was 0 . This behavior is also observed in Herschel-Bulkley fluids. In a
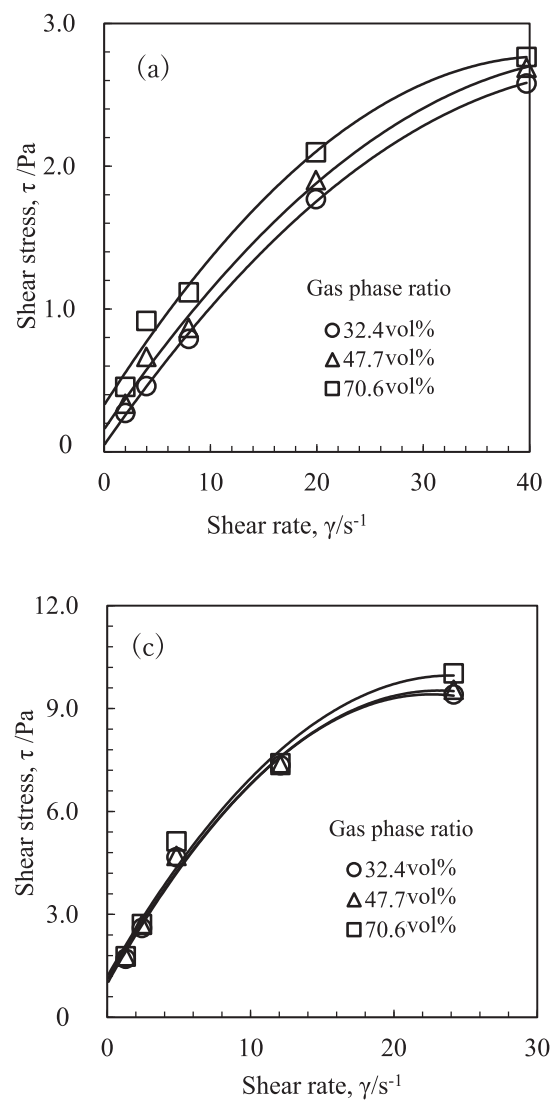

complex fluid, the yield stress is defined as the stress above which the viscoelastic behavior begins. In other words, the viscoelastic fluid exhibits elastic behavior when the shear stress of the gas-liquid-coexisting fluid induced by the reaction-generated gas exceeds the yield value and viscoelastic behavior when the shear stress exceeds the yield value. This is because the fine bubbles generated by the chemical reaction are densely arranged and the relative viscosity is governed by the surface tension of the liquid film. ${ }^{21)}$

\subsection{Empirical Modelling of Simulated Foaming Slag}

This study proposes a viscosity estimation formula, similar to the formulas reported by Frankel and Acrivos, ${ }^{22)}$ Han and King, ${ }^{23)}$ and Hinata et al., ${ }^{24)}$ that is applicable to a gas-liquid-coexisting fluid in which bubbles are dispersed in a liquid. A viscosity estimation formula using the capillary number, $C a,{ }^{25,26)}$ has also been proposed. $C a$ is expressed by the following equation:

$$
C a=\frac{\eta_{L} U}{\sigma_{L}}=\frac{\eta_{L} \gamma d}{\sigma_{L}}
$$

where $\eta / \eta_{L}$ is the relative viscosity, $\phi$ is the gas phase ratio, $U$ is the representative velocity, $\sigma$ is the surface tension of the liquid phase, $d$ is the bubble diameter, and $n$ is a coefficient. This formula is shown below:

$$
\frac{\eta}{\eta_{L}}=\frac{1+\left(\frac{5}{6} C a\right)^{2}+\phi\left(1-\frac{12}{5} C a^{2}\right)}{1+\left(\frac{5}{6} C a\right)^{2}}
$$
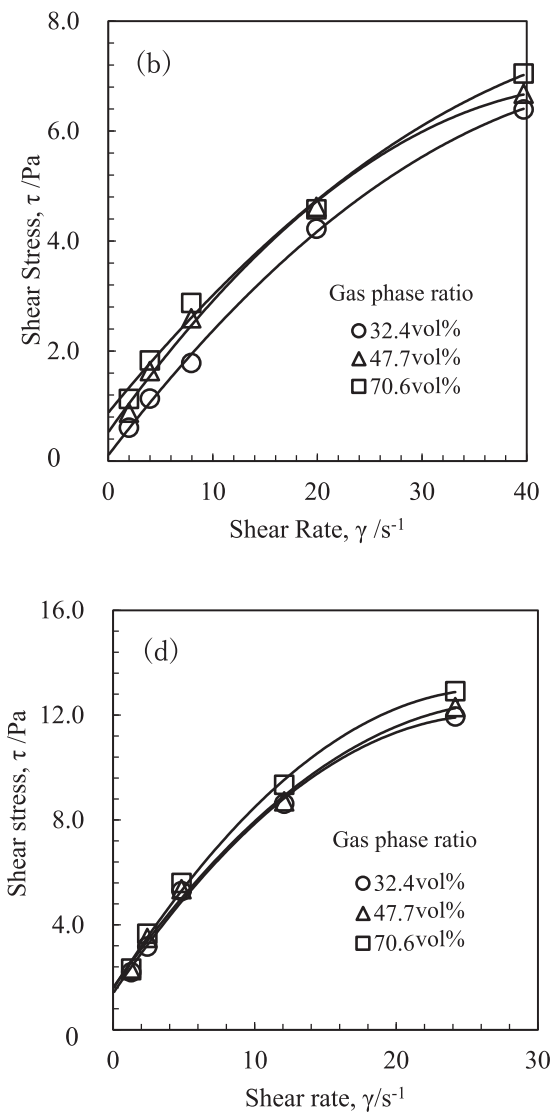

Fig. 9. Shear stress of a double-phase fluid as a function of shear rate at (a) 1.76, (b) 6.00, (c) 60.1, and (d) $100 \mathrm{mPa} \cdot \mathrm{s}$ of aq. glycerol solution. 


$$
\begin{aligned}
& \frac{\eta}{\eta_{L}}=\frac{1+\left(\frac{5}{6} C a\right)^{2}\left(1+\frac{20}{3} \phi\right)(1+4 \phi)}{1+\left(\frac{5}{6} C a\right)^{2}\left(1+\frac{20}{3} \phi\right)^{2}}\left(1+\phi+\frac{5}{2} \phi^{2}\right) \\
& \frac{\eta}{\eta_{L}}=\left(\frac{0.45+1.3 \phi}{C a^{\frac{1}{6}}}\right) \phi
\end{aligned}
$$

where $\eta, \eta_{\mathrm{L}}$ and $\phi$ are the viscosity of the dispersed gas phase, viscosity of the liquid phase, and gas phase ratio, respectively. In addition, some of the authors employed the same measurement device as in this study to create a viscosity estimation formula for a simulated foaming slag in which $\mathrm{N}_{2}$ gas was blown into silicone oil. ${ }^{13)}$ The equation is obtained by multiple regression analysis to obtain the apparent viscosity value. ${ }^{27)}$

$$
\begin{gathered}
\frac{\eta}{\eta_{L}}=(1-\phi)^{-n} \\
n=0.148 C a^{-0.371}
\end{gathered}
$$
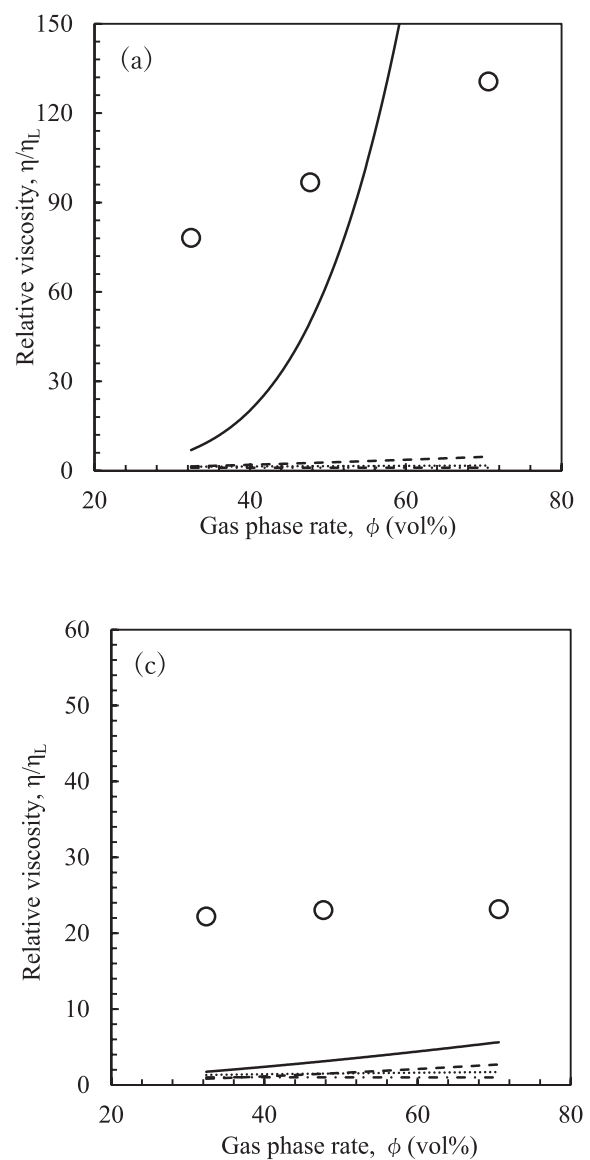

Below, we introduce a parameter called global delta ${ }^{28)}$ that shows the relative difference.

$$
\begin{aligned}
& \delta_{n}=\frac{\left(\mu_{n}\right)_{c a l}-\left(\mu_{n}\right)_{\text {mea }}}{\left(\mu_{n}\right)_{c a l}} \times 100 \\
& \Delta=\frac{1}{N} \sum_{n=1}^{N}\left|\delta_{n}\right|
\end{aligned}
$$

$\delta_{n}$ is the parameter that indicates the relative difference expressed in $\%$. $\left(\mu_{n}\right)_{\text {cal }}$ and $\left(\mu_{n}\right)_{\text {mea }}$ represent the calculated and measured values of relative viscosity, respectively. $\Delta$ (global delta) represents the average value of the absolute values of $\delta_{\mathrm{n}}$. It shows that the difference between the measured values is small and that it is a highly accurate estimation. If the value of $\Delta$ for many data is approximately $30 \%$ or less, the calculated value is generally almost equal to the uncertainty of the measured value or within the uncertainty range and can be evaluated as a highly accurate calculated value.

First, we investigated whether these estimation formulas could be applied to the measured viscosity in this study. Figure 10 shows a comparison of the measured and calculated values of relative viscosity. It was found that
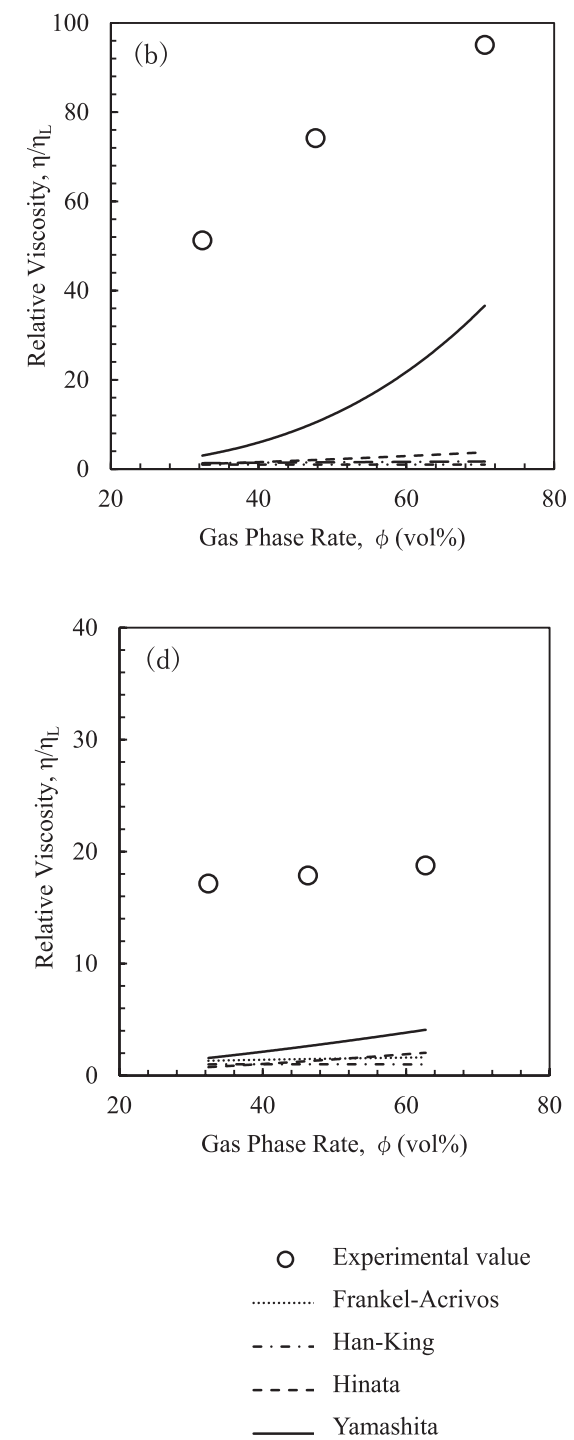

Fig. 10. Comparison of reported viscosity value for gas-phase-dispersed fluid with the experimental values of the present study at $5 \mathrm{rpm}$ ((a) 1.76, (b) 6.00, (c) 60.1, and (d) $100 \mathrm{mPa} \cdot \mathrm{s}$ of aq. glycerol solution). 
all reported viscosity values were lower than the relative viscosity values determined in this study, and thus were not reproduced.

Therefore, in this study, we focused on the EinsteinRoscoe's equation $^{29)}$ shown in Eq. (16).

$$
\frac{\eta}{\eta_{L}}=(1-a \phi)^{-n}
$$

We focused on the coefficients $a$ and $n$ when creating the equation applicable to the gas-liquid-coexisting liquid in this experiment. When the liquid phase surrounds the bubble and can move freely, as in this experiment, $a=1.0$. Because $n$ is a dimensionless number, we tried to express it using $\mathrm{Ca}$, which is a dimensionless number that is often used in Eqs. (9) to (11).

Therefore, $n$ was calculated from Eq. (12) and $\mathrm{Ca}$ was calculated from Eq. (8). The relationship between the coefficients obtained by the calculation and the number of capillaries is shown in Fig. 11. From Fig. 11, it is evident that there were three separate tendencies of the value of $n$ depending on the gas phase ratio. Figure 12 displays the relationship between $n$ and $C a$ for each gas phase ratio. From this relationship, the following formula was created by multiple regression:

$$
\begin{aligned}
& n_{32.4 \mathrm{vol} \%}=3.77 \mathrm{Ca}^{-0.122} \\
& n_{47.7 \mathrm{vol} \%}=2.20 \mathrm{Ca} \mathrm{a}^{-0.134}
\end{aligned}
$$
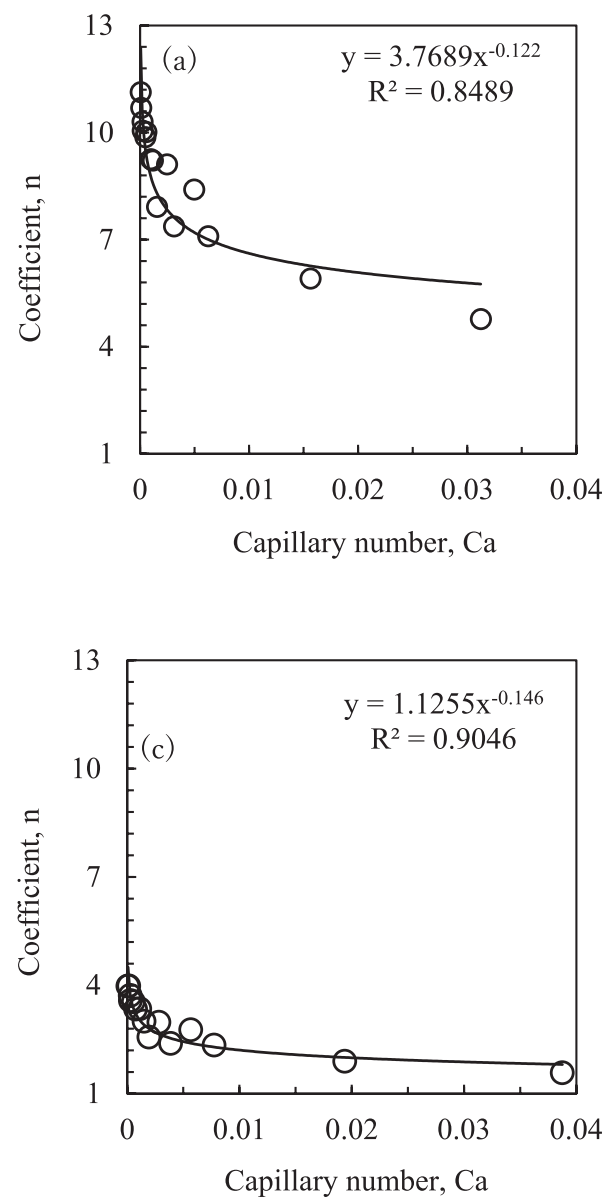

$$
n_{70.6 v o l \%}=1.13 \mathrm{Ca}^{-0.146}
$$

This equation shows that the value of $n$ decreases exponentially as $\mathrm{Ca}$ increases.

Figure 13 shows the results of comparing the relative viscosity values calculated by Eqs. (17)-(19) with the those measured in this study.

The values of $\Delta$ in (a), (b), and (c) of Fig. 13 were calcu-

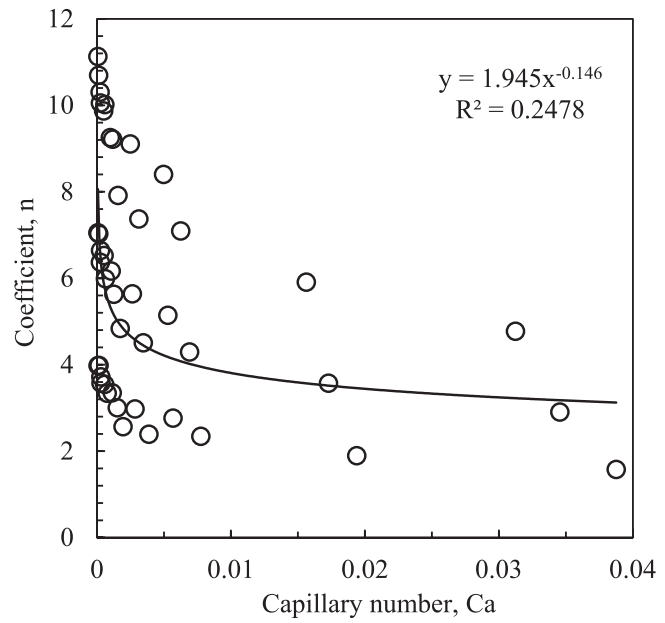

Fig. 11. Coefficient, n, of Einstein-Roscoe's equation as a function of capillary number, $\mathrm{Ca}$, calculated from the experimental conditions of the present study.

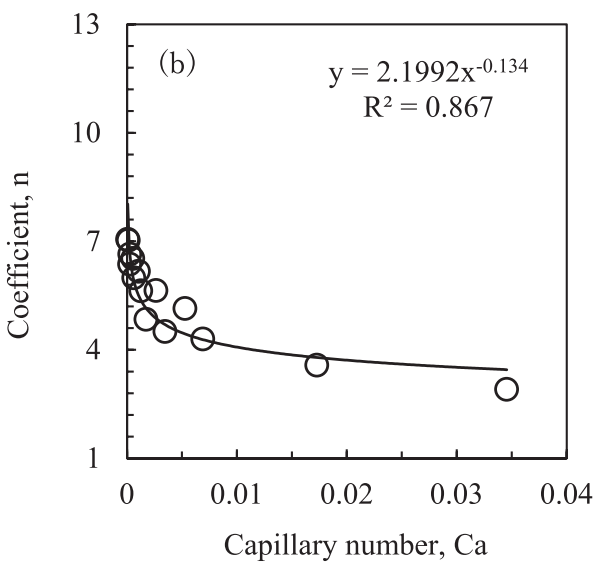

Fig. 12. Coefficient, $n$, of Einstein-Roscoe's equation as a function of capillary number, $\mathrm{Ca}$, calculated from the experimental conditions at (a) 32.4 , (b) 47.7 , and (c) 70.6 vol\% gas phase. 

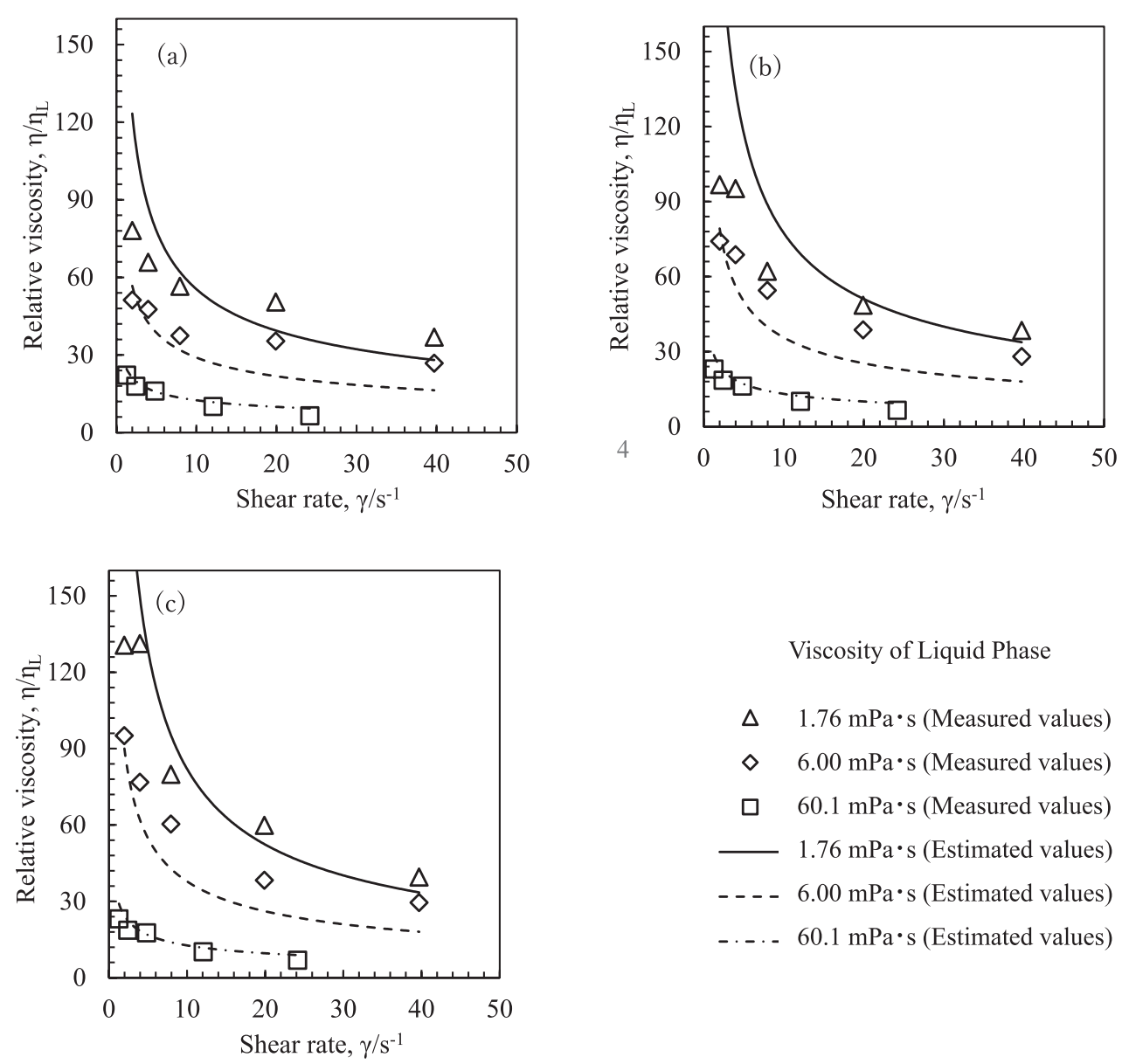

Fig. 13. Comparison of calculated viscosity proposed in present study for a double-phase fluid with estimated values at (a) 32.4 , (b) 47.7 , and (c) $70.6 \mathrm{vol} \%$ gas phase ratio.

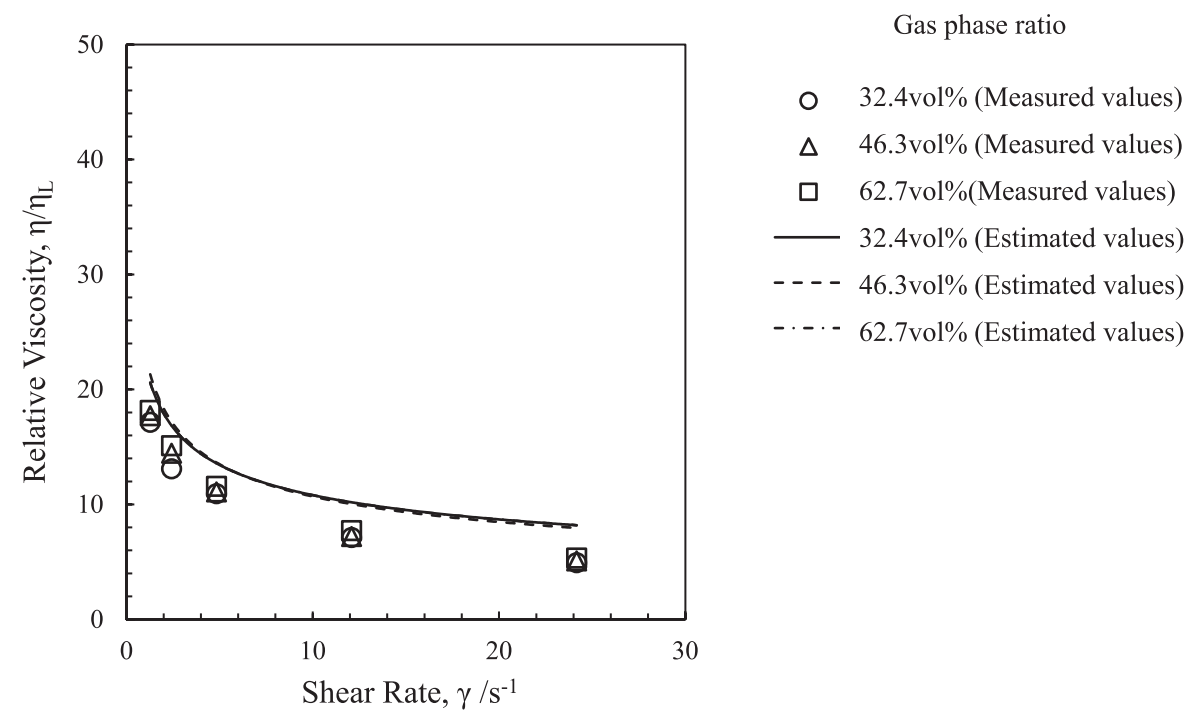

Fig. 14. Comparison of calculated viscosity proposed in present study for a double-phase fluid with estimated values at $100 \mathrm{mPa} \cdot \mathrm{s}$ of aq. glycerol solution.

lated as $23.6 \%, 26.6 \%$, and $24.5 \%$, respectively. Therefore, it can be said that the viscosity Eqs. (17)-(19) reproduce the measured values sufficiently for each gas phase ratio. However, as written, this equation can be used only at a specific gas phase ratio. Therefore, in Eq. (20), the coefficients of Eqs. (17)-(19) are summarized as a function of the gas phase ratio.

$$
n=\left(14.6 \phi^{2}-22.0 \phi+9.35\right) C a^{(-0.062 \phi-0.103)}
$$

The value of $n$ was obtained from this equation, and the calculated and measured values were compared again. In addition, the relative viscosities obtained from the estimation formula and the measured value were also compared at a liquid-phase viscosity of $100 \mathrm{mPa} \cdot \mathrm{s}$, which was not used 
for regression. The results are shown in Fig. 14. In this study, $\Delta$ is $25.2 \%$, and this viscosity formula sufficiently reproduces the viscosity value of the gas-liquid-coexisting fluid under the present conditions. Therefore, using Eqs. (16) and (20), we succeeded in proposing a model that can reproduce the $\eta$ of a wide range of simulated foaming slags.

\section{Conclusion}

At room temperature, we measured the viscosity and bubble diameter of a gas-liquid-coexisting fluid derived from internally generated gas. Following are the findings of this study.

(1) By the chemical reaction, we produced a gas-liquidcoexisting fluid from internally generated gas that is suitable for viscosity measurement.

(2) The bubble diameter increased due to the increase in the gas phase ratio and liquid-phase viscosity. The diffusion of gas inside the foam film was believed to be caused by the contact of bubbles.

(3) At a low shear rate, the apparent viscosity increased with the increase in the gas phase ratio. However, at a high liquid viscosity and high shear rate, the viscosity increased more slowly.

(4) The gas-liquid-coexisting fluid demonstrated the properties of a Herschel-Bulkley fluid.

(5) The Einstein-Roscoe viscosity estimation formula was applicable to the gas-liquid-coexisting fluid in this experiment.

\section{REFERENCES}

1) S. Hara, T. Kobayashi and K. Ogino: Tetsu-to-Hagané, 80 (1994), 306 (in Japanese). https://doi.org/10.2355/tetsutohagane1955.80.4 306

2) K. Yoshida, I. Yamazaki, Y. Tozaki, N. Aoki, J. Yoshiyama and K. Arai: Tetsu-to-Hagané, 76 (1990), 1817 (in Japanese). https://doi. org/10.2355/tetsutohagane1955.76.11_1817

3) Division of Basic Research on Slag Utilization: Tetsu-toHagané, 65 (1979), 1787 (in Japanese). https://doi.org/10.2355/ tetsutohagane1955.65.12_1787
4) G. G. Stokes: Trans. Camb. Philos. Soc., 8 (1845), 287.

5) A. Warczok and T. A. Utigard: Can. Metall. Q., 33 (1994), 205.

6) Y. Zhang and R. J. Fruehan: Metall. Mater. Trans. B, 26 (1995), 803.

7) E. J. Jung and D. J. Min: Steel Res. Int., 83 (2012), 705.

8) H. Kania, K. Nowacki and T. Lis: Metalurgija, 52 (2013), 204.

9) J. O. Sibree: Trans. Faraday Soc., 30 (1934), 325. https://doi-org/ 10.1039/TF9343000325

10) K. Uhira: Bull. Earthq. Res. Inst. Univ. Tokyo, 55 (1980), 3 (in Japanese).

11) S. S. Ghag, P. C. Hayes and H. Lee: ISIJ Int., 38 (1998), 1201. https:// doi.org/10.2355/isijinternational.38.1201

12) T. Mizu and K. Nagao: Nippon Shokuhin Kagaku Kogaku Kaishi (J. Jpn. Soc. Food Sci. Technol.), 57 (2010), 20. https://doi.org/10.3136/ nskkk.57.20

13) K. Yamashita, S. Sukenaga, M. Matsuo, N. Saito and K. Nakashima: ISIJ Int., 54 (2014), 2064. https://doi-org/10.2355/ isijinternational.54.2064

14) G. Qiu, C. Shan, X. Zhang and X. Lv: Ironmaking Steelmaking, 44 (2017), 246. https://doi.org/10.1080/03019233.2016.1210360

15) C. O. Vandu and R. Krishna: Chem. Eng. Process., 43 (2004), 987. https://doi-org/10.1016/j.cep.2003.09.007

16) W. A. Al-Masry: Chem. Eng. Technol., 24 (2001), 71. https:// doi.org/10.1002/1521-4125(200101)24:1\%3C71::AIDCEAT71\%3E3.0.CO;2-E

17) S. Hara and K. Ogino: Tetsu-to-Hagané, 78 (1992), 200 (in Japanese). https://doi.org/10.2355/tetsutohagane1955.78.2 200

18) H. Tsuge: Bull. Soc. Sea Water Sci., Jpn., 64 (2010), 4 (in Japanese). https://doi.org/10.11457/swsj.64.4

19) M. B. Sexton, M. E. Möbius and S. Hutzler: Soft Matter, 7 (2011), 11252. https://doi.org/10.1039/C1SM06445B

20) S. Cohen-Addad, R. Höhler and O. Pitois: Annu. Rev. Fluid Mech., 45 (2013), 241. https://doi.org/10.1146/annurev-fluid-011212-140634

21) H. Oiwa, K. Mitta, M. Ishikawa, Y. Murai and F. Yamamoto: Proc. JSME Annu. Meet., 6 (2003), 283 (in Japanese). https://doi. org/10.1299/jsmemecjo.2003.6.0_283

22) N. A. Frankel and A. Acrivos: J. Fluid Mech., 44 (1970), 65. https:// doi.org/10.1017/S0022112070001696

23) C. D. Han and R. G. King: J. Rheol., 24 (1980), 213. https:// doi-org/10.1122/1.549562

24) S. Hinata and M. Ohki: Bull. JSME, 14 (1971), 951. https:// doi.org/10.1299/jsme1958.14.951

25) M. Manga, J. Castro, K. V. Cashman and M. Loewenberg: J. Volcanol. Geotherm. Res., 87 (1998), 15. https://doi.org/10.1016/ S0012-821X(98)00278-7

26) A. C. Rust and M. Manga: J. Non-Newtonian Fluid Mech., 104 (2002), 53. https://doi.org/10.1016/S0377-0257(02)00013-7

27) A. M. Lejeune and P. Richet: J. Geophys. Res.: Solid Earth, 100 (1995), 4215. https://doi.org/10.1029\%2F94JB02985

28) T. Iida, Y. Kita, M. Ueda, K. Nakashima and K. Mori: YouyuusuraguGarasu-no-Nensei (Estimation of viscosities of slag and glasses), Agne Gijutsu Center, Tokyo, (2003), 76 (in Japanese).

29) R. Roscoe: Br. J. Appl. Phys., 3 (1952), 267. 